\title{
APLIKASI PENGUKURAN KUALITAS PELAYANAN PUBLIK SECARA ONLINE UNTUK MENDUKUNG SMART GOVERNMENT KOTA PEKALONGAN (ONLINE PUBLIC SERVICE QUALITY MEASUREMENT APPLICATION TO SUPPORT SMART GOVERNMENT PEKALONGAN CITY)
}

\author{
Prastuti Sulistyorini, Christian Yulianto Rusli, Indrayanti \\ STMIK Widya Pratama Pekalongan \\ Jl Patriot No 25 Pekalongan \\ Korespondensi: prastutisulistyorini@yahoo.co.id
}

\begin{abstract}
One of the factors in smart government is the existence of online services. To improve the quality of services in a sustainable manner, the government implements policies to carry out community satisfaction surveys. The survey of community satisfaction is a comprehensive measure of the level of community satisfaction derived from the measurement of public opinion. Measurement of community satisfaction index (IKM) on public services currently conducted in the Department of Population and Civil Registry and Health Office has not been done automatically by using an application. The purpose of this research is to develop a service quality measurement application that can be accessed directly by the community. Research methods used in the development of this application consists of data collection methods with interviews, observations, and questionnaires, with application development methods using linear sequential and application testing methods using blackbox testing methods. Indicators in the determination of IKM in accordance with the instructions in the MENPAN Decree No: KEP | 25 | M.PAN / 2/2004 on the general guidelines for the preparation of community satisfaction survey, which is 14 indicators. With the application of public service quality measurements that can be accessed directly by the public, the task of OPD public service providers in performing the evaluation of the performance of public service delivery can be done easily because it utilizes ICT. The existence of the application of public service satisfaction measurement that can be accessed directly (online) can support the efforts of city government pekalongan in realizing smart government.
\end{abstract}

Keywords: Quality measurement application of public service

\begin{abstract}
ABSTRAK
Salah satu faktor yang ada didalam pemerintahan cerdas (smart government) adalah adanya layanan online. Untuk meningkatkan kualitas pelayanan secara berkelanjutan, pemerintah penentapkan kebijakan untuk melaksanakan survei kepuasan masyarakat. Survei kepuasan masyarakat adalah pengukuran secara komprehensif tingkat kepuasan masyarakat yang diperoleh dari hasil pengukuran atas pendapat masyarakat. Pengukuran indeks kepuasan masyarakat (IKM) terhadap pelayanan publik yang saat ini dilakukan di Dinas Kependudukan dan Catatan Sipil dan Dinas Kesehatan belum dilakukan secara otomatis dengan menggunakan sebuah aplikasi. Tujuan dari penelitian ini adalah untuk
\end{abstract}


mengembangkan sebuah aplikasi pengukuran kualitas pelayanan yang dapat diakses secara langsung oleh masyarakat. Metode penelitian yang digunakan dalam pengembangan aplikasi ini terdiri dari metode pengumpulan data dengan wawancara, observasi, dan kuesioner, dengan metode pengembangan aplikasi menggunakan sekuensial linier serta metode pengujian aplikasi menggunakan metode pengujian blackbox. Indikator dalam penentuan IKM sesuai dengan petunjuk dalam Keputusan MENPAN No : KEP/25/M.PAN/2/2004 tentang pedoman umum penyusunan survei kepuasan masyarakat, yatu 14 indikator. Dengan adanya aplikasi pengukuran kualitas pelayanan publik yang dapat diakses secara langsung oleh masyarakat, tugas OPD penyelenggara pelayanan publik dalam melakukan evaluasi kinerja penyelenggaraan pelayanan publik dapat terlaksana dengan mudah karena memanfaatkan TIK. Adanya aplikasi pengukuran kepuasan pelayanan publik yang dapat diakses secara langsung (online) ini dapat mendukung upaya pemerintah kota pekalongan dalam mewujudkan smart government.

Kata Kunci : Aplikasi pengukuran kualitas pelayanan publik

\section{PENDAHULUAN}

Dalam rangka meningkatkan kualitas pelayanan publik secara berkelanjutan, pemerintah menetapkan kebijakan untuk melaksanakan survei kepuasan masyarakat bagi instansi penyelenggara pelayanan publik. Kegiatan survei kepuasan masyarakat sangat penting untuk mengetahui kualitas pelayanan publik serta mendapatkan masukan dari pengguna layanan dalam rangka perbaikan pelayanan kepada masyarakat oleh penyelenggara pelayanan publik.

Dengan adanya peraturan tersebut diharapkan agar seluruh penyelenggara pelayanan publik dapat melakukan survei kepuasan masyarakat, baik di tingkat Pemerintah Pusat maupun di tingkat Pemerintah daerah. Pelaksanaan survei kepuasan masyarakat ini penting, selain untuk mengukur kepuasan masyarakat sebagai pengguna pelayanan juga meningkatkan kualitas penyelenggaraan pelayanan publik. Mengingat begitu pentingnya pelaksanaan survei kepuasan masyarakat ini, diharapkan agar penyelenggara pelayanan publik dapat melaksanakan survei kepuasan masyarakat minimal 1 tahun sekali.

Berdasarkan hasil wawancara maupun observasi dengan Dinas Kependudukan dan Catatan Sipil, serta Dinas Kesehatan Pemerintah Kota Pekalongan, bahwa Pengukuran kualitas pelayanan masih dilakukan secara manual dengan menggunakan potongan kertas yang berwarna maupun menggunakan kancing yang berwarna sesuai dengan jenis layanan yang dipilih. Apabila pengisian kuesioner dilakukan sendiri oleh penerima layanan, sering terjadi penerima layanan kurang aktif melakukan pengisian sendiri meskipun sudah ada himbaun. Bahwa dalam pengukuran indeks kepuasan masyarakat karena dilakukan oleh unit pelayanan sendiri sehingga hasilnya kurang objektif. Pelaporan IKM belum dilakukan secara otomatis sehingga laporan hasil pengukuran IKM tidak cepat tersedia.

Pembuatan aplikasi pengukuran kualitas pelayanan publik secara online untuk mendukung smart goverment kota pekalongan sebagai salah satu bentuk inovasi 
pelayanan publik. Indikator dalam penentuan tingkat kualitas pelayanan publik sesuai dengan petunjuk dalam Keptusan MENPAN No : KEP/25/M.PAN/2/2004 tentang pedoman umum penyusunan survei kepuasan masyarakat, yatu 14 indikator. Indikator tersebut meliputi prosedur pelayanan, persyaratan pelayanan, kejelasan petugas pelayanan, kedisiplinan petugas pelayanan, tangung jawab petugas pelayanan, kemampuan petugas pelayanan, kecepatan pelayanan, keadilan mendapatkan pelayanan, kesopanan dan keramahan petugas, kewajaran biaya pelayanan, kepastian biaya pelayanan, kepastian jadwal pelayanan, kenyamanan lingkungan, dan keamanan pelayanan.

Aplikasi survei kepuasan pelayanan publik ini diharapkan dapat mendukung upaya pemerintah kota pekalongan dalam mewujudkan smart government. Smart government merupakan istilah yang merujuk pada pengimplementasian TIK pada layanan publik di bidang pemerintahan secara efektif. Salah satu faktor yang ada didalam pemerintahan cerdas (smart government) adalah adanya layanan online. Smart government salah satu elemen dasar yang harus dipenuhi untuk mewujudkan smart city.

\section{RUMUSAN MASALAH}

Berdasarkan latar belakang yang diuraikan atas, dapat diketahui bahwa permasalahan yang terjadi di OPD penyelenggara pelayanan publik adalah belum adanya aplikasi pengukuran kualitas pelayanan publik yang dapat diakses secara langsung oleh masyarakat, maka rumusan masalah dari penelitian ini adalah bagaimana membangun sebuah aplikasi pengukuran kepuasan pelayanan publik secara online.

\section{TINJAUAN PUSTAKA}

\subsection{Pelayanan Publik}

Pengertian pelayanan publik adalah serangkaian aktivitas yang dilakukan oleh birokrasi publik untuk memenuhi kebutuuhan warga pengguna. Pengguna yang dimaksudkan disini adalah warga negara yang membutuhkan pelayanan publik, seperti pembuatan Kartu Tanda Penduduk (KTP), akta kelahiran, akta nikah, akta kematian, sertifikat tanah, izin usaha, Izin Mendirikan bangunan, izin gangguan ( $\mathrm{HO}$ ), izin mengambil air tanah, berlangganan air minum, listrik dan sebagainya (Dwiyanto 2006).

Berdasarkan Undang Undang No. 25 Tahun 2009 tentang Pelayanan Publik yaitu : pelayanan publik adalah segala bentuk kegiatan dalam rangka pengaturan, pembinaan, bimbingan, penyediaan fasilitas, jasa dan lainnya yang dilaksanakan oleh aparatur pemerintah sebagai upaya pemenuhan kebutuhan kepada masyarakat sesuai ketentuan perundang-undangan yang berlaku.

Pelayanan publik diartikan pemberian layanan (melayani) keperluan orang atau masyarakat yang mempunyai kepentingan pada organisasi tertentu sesuai dengan aturan pokok dan tata cara yang telah ditetapkan (Litjan Poltak Sinambela, dkk 2011). 
Dari definisi tesebut diatas, maka dapat disimpulkan bahwa pelayanan publik adalah segala bentuk jasa pelayanan baik dalam bentuk barang publik maupun jasa publik yang pada prinsipnya menjadi tanggung jawab dan dilaksanakan oleh Instansi Pemerintah di Pusat, di Daerah, dan di lingkungan Badan Usaha Milik Negara atau Usaha Milik Daerah, dalam rangka upaya pemenuhan kebutuhan masyarakat maupun dalam rangka pelaksanaan ketentuan peraturan perundang-undangan.

\subsection{Kualitas Pelayanan Publik}

Kata "kualitas" mengandung banyak definisi dan makna. Orang yang berbeda akan mengartikannya secara berlainan. Jika dihubungkan dengan administrasi publik, maka definisi kualitas menurut (Litjan Poltak Sinambela, dkk 2011), biasanya menggambarkan karakteristik langsung dari suatu produk, seperti:

1. kinerja (performance).

2. keandalan (reliability).

3. mudah dalam penggunaan (easy of use).

4. estetika (esthetics).

Tujuan pelayanan publik pada dasarnya adalah untuk memuaskan masyarakat. Menurut (Litjan Poltak Sinambela, dkk 2011), bahwa untuk mencapai kepuasan itu dituntut kualitas pelayanan prima yang tercermin dari:

1. transparansi, yakni pelayanan yang bersifat terbuka, mudah dan dapat diakses oleh semua pihak yang membutuhkan dan disediakan secara memadai serta mudah dimengerti.

2. akuntabilitas, yakni pelayanan yang dapat dipertanggungjawabkan sesuai dengan ketentuan peraturan perundang-undangan.

3. kondisional, yakni pelayanan yang sesuai dengan kondisi dan kemampuan pemberi dan penerima pelayanan dengan tetap berpegang pada prinsip efisiensi dan efektivitas.

4. partisipatif, yaitu pelayanan yang dapat mendorong peran serta masyarakat dalam penyelenggaraan pelayanan publik dengan memperhatikan aspirasi, kebutuhan dan harapan masyarakat.

5. kesamaan hak, yaitu pelayanan yang tidak melakukan diskriminasi dilihat dari aspek apa pun khususnya suku, ras, agama, golongan, status sosial, dan lainlain

6. keseimbangan hak dan kewajiban, yaitu pelayanan yang mempertimbangkan aspek keadilan antara pemberi dan penerima pelayanan publik.

\subsection{Indeks Kepuasan Masyarakat (IKM)}

Berdasarkan Keputusan MENPAN No : KEP/25/M.PAN/2/2004, Indeks Kepuasan Masyarakat (IKM) adalah data dan informasi tentang tingkat kepuasan masyarakat yang diperoleh dari hasil pengukuran secara kuantitatif dan kualitaif atas pendapat masyarakat dalam memperoleh pelayanan dari aparatur penyelenggara pelayanan publik dengan membandingkan antara harapan dan kebutuhannya. Menurut Keputusan MENPAN No : KEP/25/M.PAN/2/2004 tersebut terdapat 14 unsur yang relevan, valid dan reliable, sebagai unsur minimal 
yang harus ada sebagai dasar pengukuran indeks kepuasan masyarakat, yaitu: prosedur pelayanan, persyaratan pelayanan, kejelasan petugas pelayanan, kedisiplinan petugas pelayanan, tanggung jawab petugas pelayanan, kemampuan petugas pelayanan, kecepatan pelayanan, keadilan mendapatkan pelayanan, kesopanan dan keramahan petugas, kewajaran biaya pelayanan, kepastian biaya pelayanan, kepastian jadwal pelayanan, kenyamanan lingkungan, dan keamanan pelayanan. Adapun langkah-langkah untuk mengolah IKM adalah sebagai berikut :

1. Membuat scoring/nilai persepsi untuk setiap alternatif jawaban.

2. Mengitung bobot nilai rata-rata tertimbang untuk setiap unsur pelayanan dengan rumus :

Bobot nilai rata-rata tertimbang $=\frac{\text { jumlah bobot }}{\text { jumlah unsur }}=\frac{1}{4}=0,071$

3. Menghitung IKM dengan rumus sebagai berikut :

$\mathrm{IKM}=$ Total dari nilai persepsi per unsur $\mathrm{X}$ nilai penimbang

Total unsur yang terisi

4. Untuk memudahkan intepretasi terhadap penilaian IKM yaitu antara 25 100, maka hasil penilaian IKM dikonversikan dengan nilai dasar 25 dengan rumus :

IKM unit pelayanan * 25

Selanjutnya nilai persepsi, interval IKM, interval konversi IKM, Mutu Pelayanan, dan Kinerja Unit Pelayanan dapat dilihat pada tabel berikut :

Tabel 2.1. Nilai Persepsi IKM

\begin{tabular}{c|c|c|c|c} 
No & Nilai Interval & Konversi IKM & $\begin{array}{c}\text { Mutu } \\
\text { Pelayanan }\end{array}$ & $\begin{array}{c}\text { Kinerja Unit } \\
\text { Pelayanan }\end{array}$ \\
\hline 1 & $1,00-1,75$ & $25-43,75$ & D & $\begin{array}{c}\text { Sangat Tidak } \\
\text { Baik }\end{array}$ \\
\hline 2 & $1,75-2,50$ & $43,76-62,50$ & C & Tidak Baik \\
\hline 3 & $2,50-3,25$ & $62,51-81,25$ & B & Baik \\
\hline 4 & $3,25-4,00$ & $81,26-100,00$ & A & Sangat Baik
\end{tabular}

\section{METODE PENELITIAN}

\subsection{Metode Pengumpulan Data}

a. Pengamatan atau Observasi

Observasi digunakan untuk mengumpulkan data melalui pengamatan langsung yang dilakukan di Dinas Kependudukan dan Catatan Sipil, Dinas Kesehatan, dan Puskesmas Bendan Kota Pekalongan.

b. Wawancara atau interview

Wawancara dilakukan kepada petugas yang menangani pengolahan data kusioener kepuasan masyarakat Kegiatan wawancara dilakukan untuk mengetahui permasalahaan yang dihadapi, maupun kebutuhan aplikasi yang yang dikendaki oleh OPD. 
c. Kuesioner

Pengumpulan data dengan membagikan kuesioner kepada 7 orang pejabat/petugas yang menangani kegiatan pengukuran tingkat kepuasan masyarakat, yaitu sejumlah 7 orang. Skala pengukuran menggunakan metode skala Likert. Tujuan diberikan kuesioner adalah untuk mengetahui prosentase responden yang mempunyai pemahaman tentang pengolahan data IKM dan pengaruh penggunaan aplikasi IKM untuk mempermudah dalam pengolahan maupun pelaporan IKM.

\subsection{Metode Pengembangan Sistem}

Berikut tahapan-tahapan yang dilakukan dengan menggunakan metode sekuensial linier :

1. Analisis, kegiatan yang dilakukan adalah dengan :

a. Analisis Permasalahan

Pada tahap ini dilakukan analisis masalah yang muncul dari sistem yang sudah berjalan dan kendala-kendala yang dihadapi oleh OPD penyelenggara pelayanan. Berdasarkan hasil wawancara dengan responden bahwa permasalahan yang dihadapi :

1. Pengukuran kualitas pelayanan masih dilakukan secara manual dengan menggunakan potongan kertas yang berwarna maupun menggunakan kancing yang berwarna sesuai dengan jenis layanan yang dipilih.

2. Apabila pengisian kuesioner dilakukan sendiri oleh penerima layanan, sering terjadi penerima layanan kurang aktif melakukan pengisian sendiri meskipun sudah ada himabuan.

3. Bahwa dalam pengukuran indeks kepuasan masyarakat karena dilakukan oleh unit pelayanan sendiri sehingga hasilnya kurang objektif.

4. Pelaporan IKM belum dilakukan secara otomatis sehingga laporan hasil pengukuran IKM tidak cepat tersedia.

b. Analisis Kebutuhan User

Pada tahap ini dilakukan analisis kebutuhan user. Analisis kebutuhan user dilakukan dengan menggunakan wawancara maupun kuesioner yang dibagikan kepada OPD penyelenggara pelayanan publik. Dari hasil hasil wawancara maupun kuesioner didapat kebutuhan user sebagai berikut :

1. Kebutuhan Fungsional.

Kebutuhan fungsional merupakan kebutuhan yang menyangkut fungsi pokok dari aplikasi pengukuran kualitas pelayanan publik yang akan dibangun, yaitu :

a. Aplikasi memiliki fasilitas untuk memilih OPD dan unit pelayanan yang diinginkan responden.

b. Aplikasi memiliki fasilitas untuk mengentri biodata responden 
c. Aplikasi memiliki fasilitas untuk mengentri survei

d. Aplikasi memiliki fasilitas untuk login super admin dan admin OPD

e. Aplikasi memiliki fasilitas pengaturan super admin dan admin OPD

f. Aplikasi memiliki fasilitas untuk memanajemen OPD/SKPD

g. Aplikasi memiliki fasilitas untuk memanajemen Unit Pelayanan

h. Aplikasi memiliki fasilitas untuk memanajemen mengelola Pertanyaan survei

i. Aplikasi dapat menampilkan laporan hasil survei, terdiri dari :

a. Responden menurut jenis kelamin

b. Responden menurut umur

c. Responden Menurut Pekerjaan

d. Responden Menurut Pendidikan

e. Indeks Kepuasan Masyarakat (IKM)

f. Export hasil survei ke excell

2. Kebutuhan Non Fungsional

Merupakan kebutuhan tambahan yang dapat mendukung kebutuhan fungsional yaitu :

a. Interface aplikasi dibuat sederhana agar mudah dioperasikan oleh pengguna.

b. Interface jawaban responden dibuat menarik dan sederhana yaitu dalam bentuk emoticon.

2. Desain

Pada tahap desain dilakukan dengan mendesain pembuatan program aplikasi berdasarkan analisis yang telah dilakukan sebelumnya yaitu analisis permasalahan dan kebutuhan yang dibutuhkan user agar dapat diimplementasikan menjadi program pada tahap selanjutnya. Perancangan yang dilakukan meliputi perancangan proses dengan menggunakan diagram use case sistem dan perancangan basis data dengan menggunakan E-RD.

3. Pengkodean dan Pengujian

Pada tahap ini dilakukan pengkodean program sesuai dengan rancangan yang telah dibuat baik database maupun tampilan sistem yang dibangun. Bahasa yang digunakan dalam pembuatan program adalah HTML, PHP, CSS dan Javascript. Text editor yang digunakan adalah Notepad++. PHP atau Hypertext Processor merupakan bahasa pemrograman yang digunakan untuk pembuatan dan pengembangan web dan bisa digunakan bersamaan dengan HTML. Sedangkan penggunaan CSS (cascading tyle sheets) dan javascript mempunyai fungsi lain yaitu membuat 
halaman web yang interaktif dan menyediakan akses script pada objek yang dibenamkan (embedded).

Setelah dilakukan pengkodean, langkah berikutnya adalah menguji sistem. Pengujian sistem dilakukan dengan pengujian blackbox. Pengujian blackbox merupakan pengujian yang berfokus pada spesifikasi fungsional dari aplikasi.

\section{HASIL DAN PEMBAHASAN}

\subsection{Hasil Perancangan Antarmuka}

a. Halaman Beranda User Masyarakat

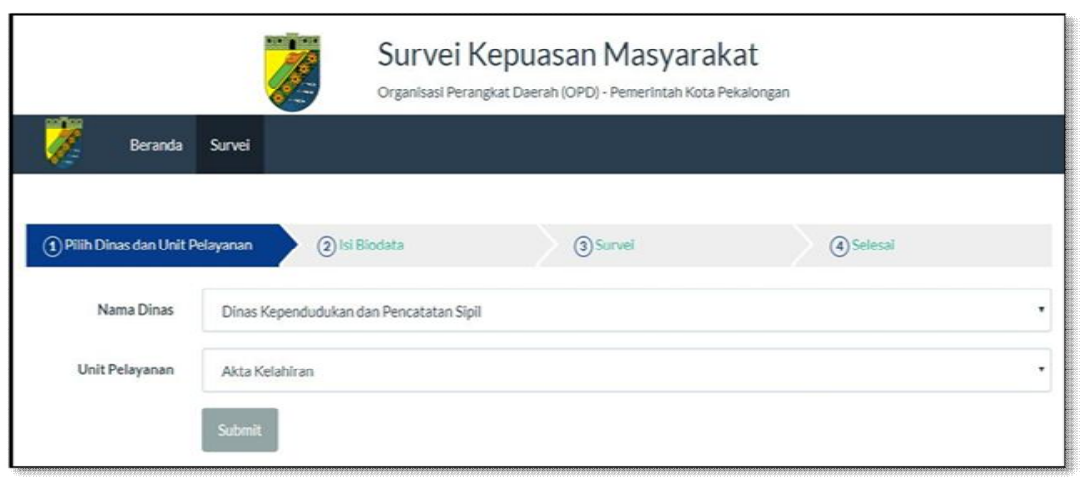

b. Halaman Sub Menu Input Biodata Responden

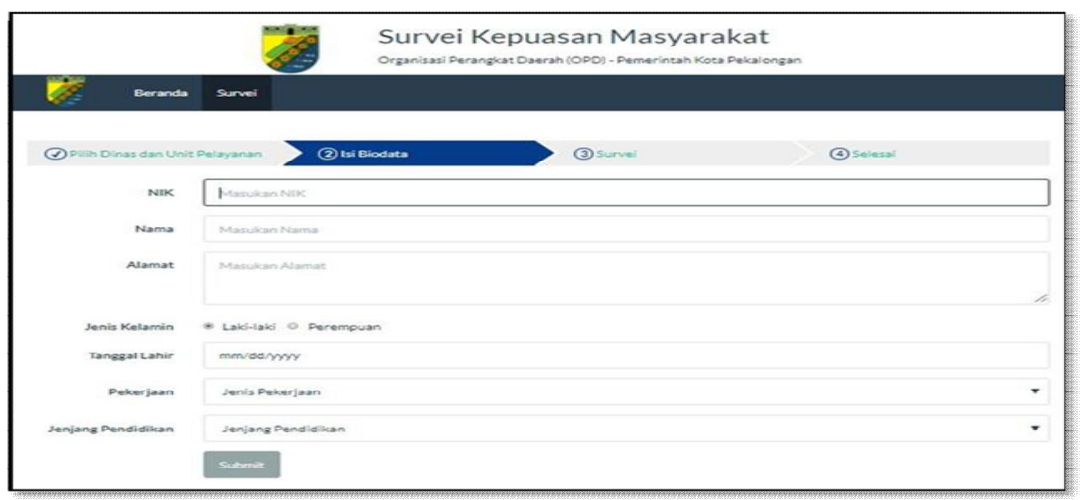

c. Halaman Sub Menu Input Survei Unsur 1

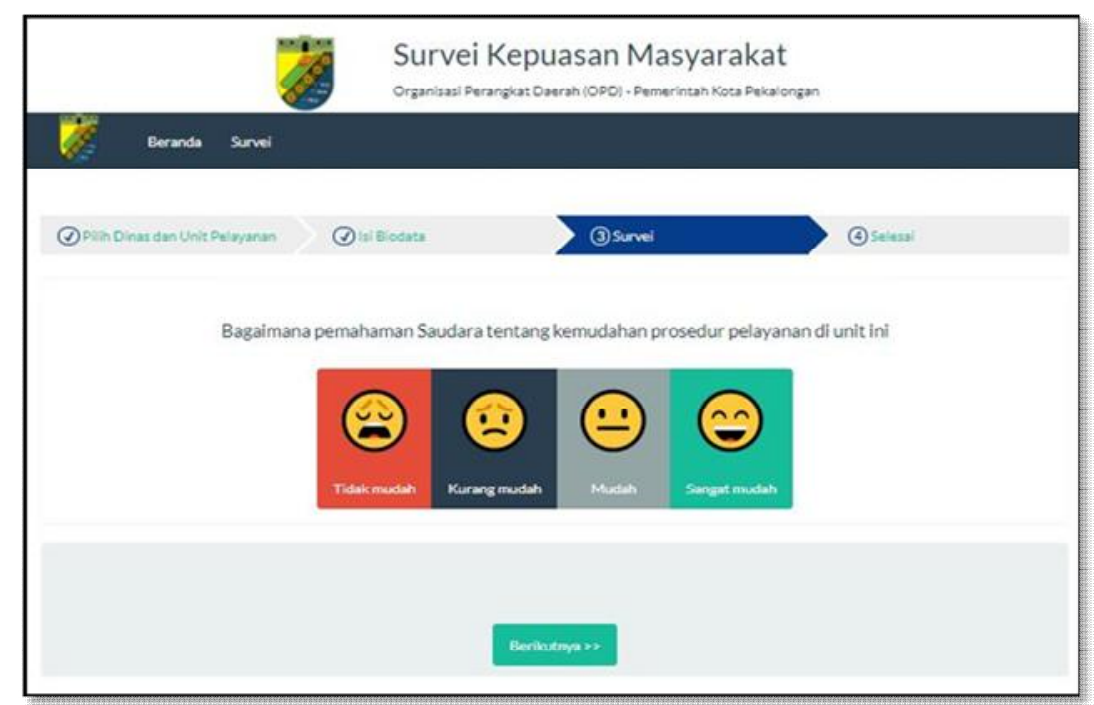


d. Halaman Hasil Survei Detail Admin OPD/SKPD

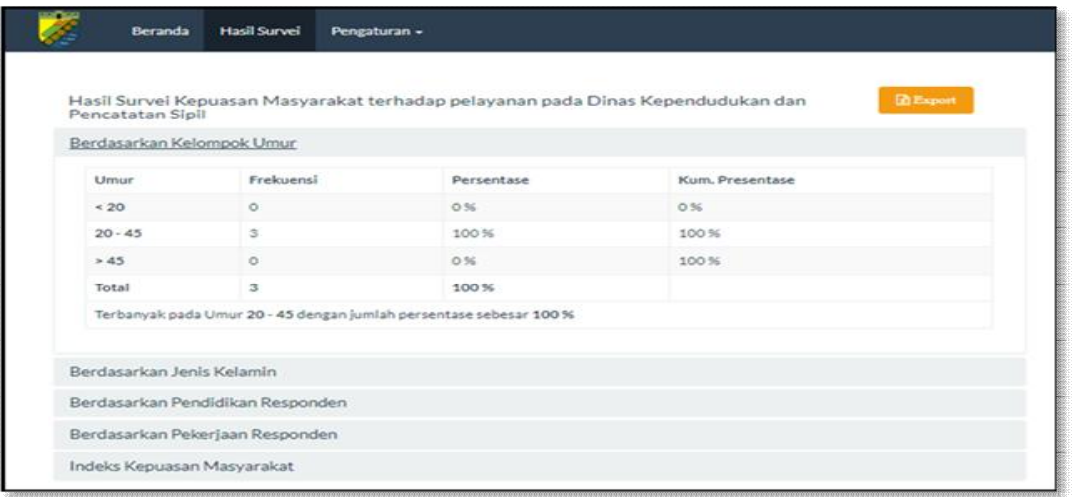

\subsection{Hasil Perancangan Basis Data}

a. Desain Tabel General Setting

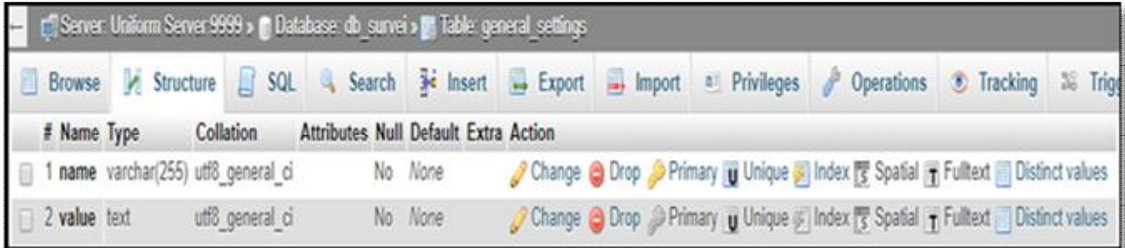

b. Desain Tabel Master Admin

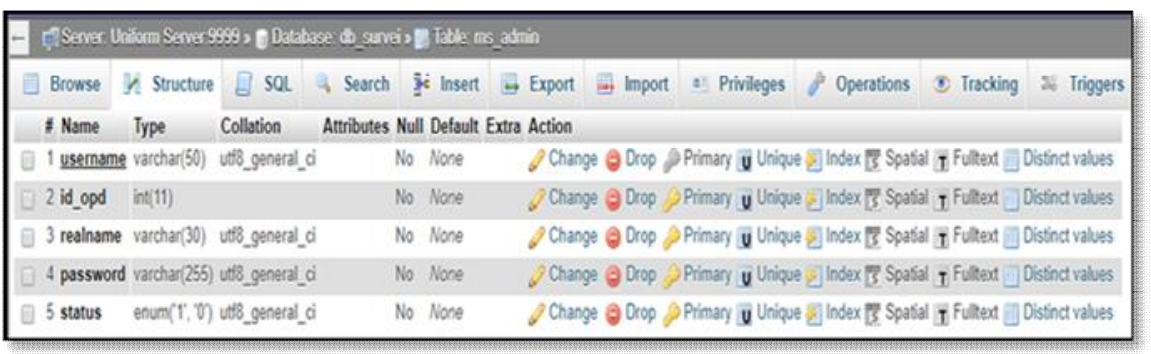

c. Desain Tabel Master OPD

\begin{tabular}{|c|c|c|c|c|}
\hline \multicolumn{5}{|c|}{ 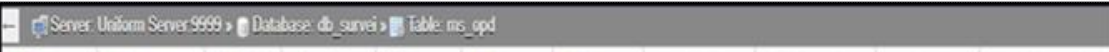 } \\
\hline D Browse KS Structure & DS Sal \& Search & $\hat{j}$ insert & $\exists$ Export If Import as Privileges Operations & (3) Tracking at Triggers \\
\hline I Name & Collation & Null Defautt & Action & \\
\hline Q 1 ideod int(11) & & No None & AUTO_NCREMENT o Change $\theta$ Orop p Primary ou Unique & Index $\bar{E}$ Spatal if Fultext $\nabla$ More \\
\hline 2 nama_opd varchar 255 & uts general $a$ & No None & DChange O Drop p Primary qu Urique & Index $\overline{E S}$ Spasal I Fultext $\nabla$ More \\
\hline (1) 3 alamat_opd tent & Wtis general di & No None & 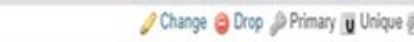 & 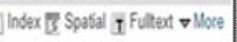 \\
\hline 4 status_opd enum( $(T$, V) & wets general di & No None & OChange Orop Pinay U U Uhique & Insex $\overline{3}$ Spasal I F Futtext $\nabla$ Moce \\
\hline
\end{tabular}

d. Tabel Master Unit Pelayanan

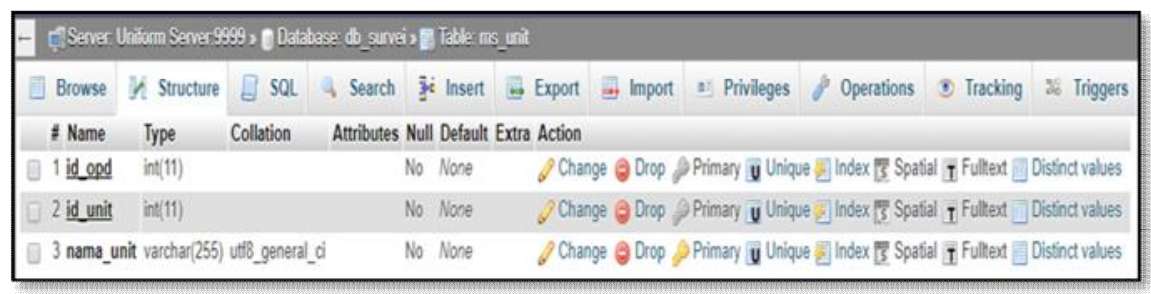


e. Tabel Responden

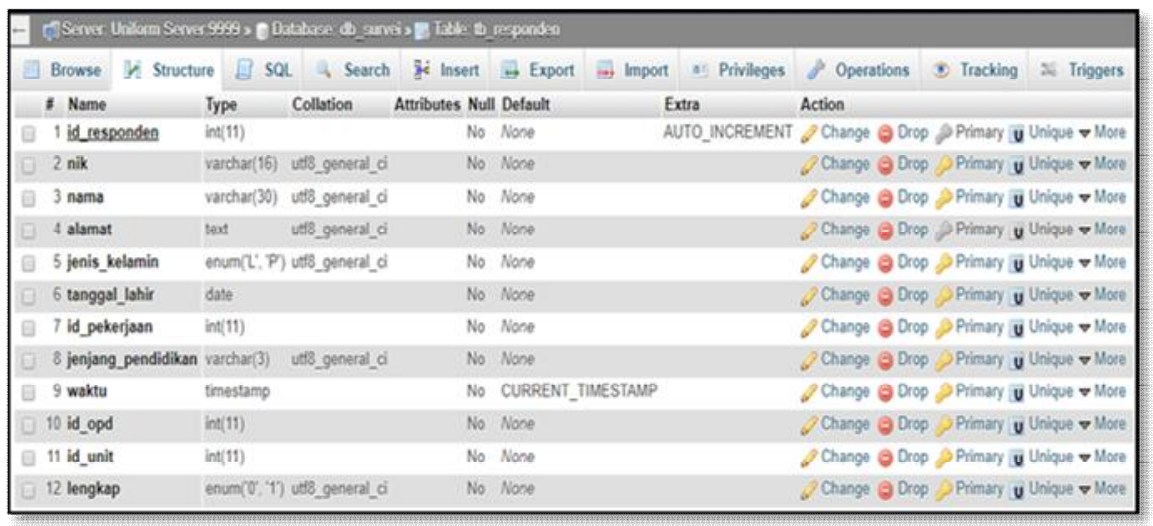

f. Tabel Pertanyaan

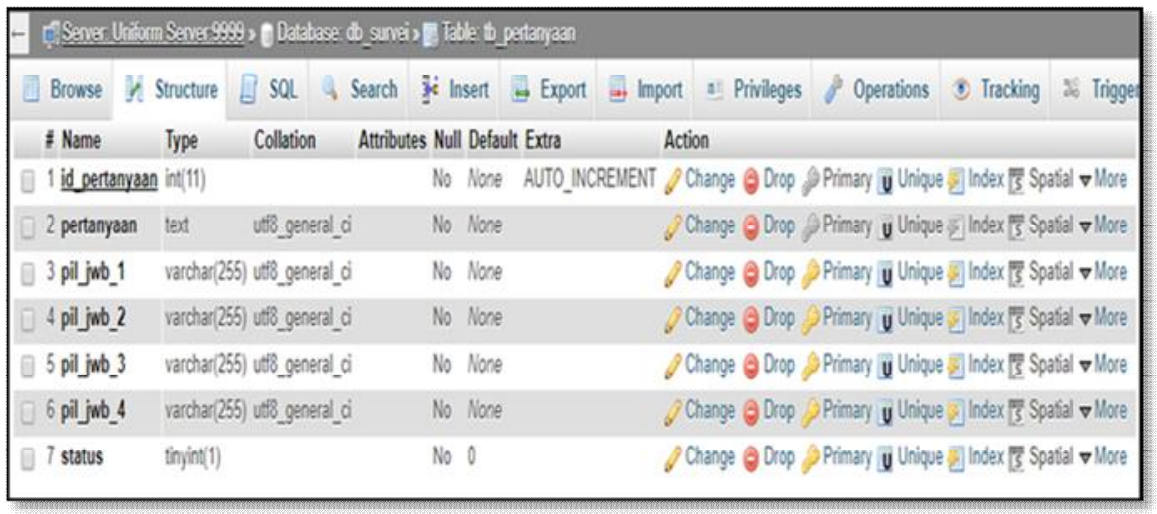

\section{KESIMPULAN DAN SARAN}

\subsection{Kesimpulan}

Berdasarkan permasalahan dan pemecahan masalah yang telah dibahas sebelumnya, maka dapat disimpulkan bahwa aplikasi pengukuran kualitas pelayanan publik secara online untuk mendukung smart government kota pekalongan sudah sesuai dengan pemecahan masalah yang sudah dianalisa sebelumya. Kebutuhan fungsional dan non fungsional yang diinginkan user sudah terwujud dalam aplikasi dan sudah sesuai dengan keinginkan user.

\subsection{Saran}

Untuk mempermudah dan mempercepat proses pengukuran tingkat kepuasan masyarakat oleh OPD penyelenggara pelayanan publik, disaran sebagai berikut :

1. Mengiimplementasikan secara nyata aplikasi pengukuran kualitas pelayanan publik secara online. Dengan diimplementasikannya aplikasi ini akan memudahkan OPD penyelenggara pelayanan publik melakukan pengukuran kualitas pelayanan publik.

2. OPD penyelenggara pelayanan publik perlu menyiapkan anjungan komputer PC/Tablet khusus di tempat / gedung pelayanan publik untuk implementasi aplikasi, yang diletakkan di tempat yang mudah dijangkau oleh masyarakat penerima layanan. 
3. Perlu dibuat kebijakan atau prosedur yang mengatur kewajiban atau keharusan bagi masyarakat mengisi aplikasi tersebut setelah menerima pelayanan.

4. Untuk mengatur komunikasi diantara beberapa komputer, dapat digunakan protokol HTTPS guna menjaga keamanan.

5. Untuk integrasi data responden dapat menggunakan NIK yang dihubungkan dengan Dinas Kependudukan dan Catatan Sipil.

\section{DAFTAR PUSTAKA}

A. Suhendar dan Hariman Gunadi. Visual Modelling Menggunakan UML dan Rational Rose. Bandung: Informatika, 2002.

Dharwiyanti, Sri dan Romi Satria Wahono. Pengantar Unified Modelling Language (UML), 2003 http://www.ilmukomputer.com. Diakses tanggal 11 Oktober 2017.

Dwiyanto, Agus. Mewujudkan Good Governance Publik. Yogyakarta: UGM Press, 2006.

Fathansyah. Sistem Basis Data. Bandung: Informatika , 2012.

Jogiyanto, HM. Analisis dan Desain Sistem Informasi. Yogyakarta: Andi Offset, 2005.

Kadir, Abdul. Dasar Pemrograman Web Dinamis Menggunakan PHP. Yogyakarta: Andi Ofset, 2001.

Litjan Poltak Sinambela, dkk. Reformasi Pelayanan Publik Teori, Kebijakan, Implementasi. Jakarta: Bumi Aksara, 2011.

Pekalongan, Pemerintah Kota. Panduan Riset Tematik. Pekalongan, 2017.

Prasetio, Adhi. Buku Pintar Pemrograman Web. Jakarta: Media Kita, 2012.

Pressman, Roger S. Rekayasa Perangkat Lunak Pendekatan Praktisi (Buku Satu). Yogyakarta: Andi Offset, 2002.

Ratminto dan Atik Septi Winarsih. Manajemen Pelayanan. Yogyakarta: Pustaka

Zeithaml, V.A., A.Parasuraman, dan L.L. Berry. Delivering Quality Service. New York: Simon and Schuster, 1990.

Keputusan Menteri Pendayagunaan Aparatur Negara No. 63 Tahun 2009 Tentang Pelayanan Publik

Keputusan Menteri Pendayagunaan Aparatur Negara No : KEP/25/M.PAN/2/2006 Tentang Indeks Kepuasan Komsumen

Undang-Undang No. 25 Tahun 2009 Tentang Pelayanan Publik 